\title{
Avaliação da atividade antimicrobiana de antissépticos e desinfetantes utilizados em um serviço público de saúde
}

\author{
Evaluation of antimicrobial activity antiseptics and disinfectants used \\ in a public health service \\ Evaluación de la actividad antimicrobiana de los antisépticos y desinfectantes utilizados \\ en un servicio de salud pública
}

\author{
Lúcia Margarete dos Reis', Bruno Ribeiro Rabello", Claudia Ross"', Lucio Mauro Rocker dos Santos ${ }^{\text {IV }}$ \\ ' Universidade Estadual de Londrina, Hospital Universitário Regional do Norte do Paraná. Londrinas-PR, Brasil. \\ " Universidade Estadual de Maringá, Programa de Pós-Graduação em Química. (Mestrando) Maringá-PR, Brasil. \\ II' Universidade Estadual do Oeste do Paraná, Curso de Enfermagem. Cascavel-PR, Brasil. \\ IV Universidade Norte do Paraná, Curso de Enfermagem. Arapongas-PR, Brasil.
}

Submissão: 06-10-2010 Aprovação: 03-11-2011

\begin{abstract}
RESUMO
O estudo teve como objetivo determinar in vitro a atividade antimicrobiana de antissépticos e desinfetantes utilizados no serviço de atenção primária à saúde de uma cidade do norte do Paraná, utilizando microrganismos padronizados pelo Instituto Nacional de Controle de Qualidade em Saúde da Fundação Oswaldo Cruz. Para tanto, foram realizadas análises da atividade antimicrobiana e da estabilidade química de três diferentes antissépticos e um desinfetante utilizados no serviço de atenção primária à saúde. A partir das análises realizadas no primeiro, sétimo, décimo quarto e vigésimo primeiro dias, após a abertura dos frascos, verificou-se que as amostras mantiveram sua atividade antimicrobiana in vitro em relação às cepas padronizadas, evidenciadas pela ausência de crescimento de unidades formadoras de colônias e estabilidade química dos princípios ativos dos antissépticos. O estudo permitiu verificar a eficácia das amostras frente a análises microbiológicas in vitro utilizando microrganismos padronizados.

Descritores: Desinfetantes; Antissépticos; Microrganismos.
\end{abstract}

\begin{abstract}
The study aimed to determine the in vitro antimicrobial activity of antiseptics and disinfectant used in the care service primary health of a city in northern Paraná, using microorganisms standardized by the National Institute of Quality Control in Health, Oswaldo Cruz Foundation. For this purpose, we performed tests of antimicrobial activity and chemical stability of three samples of antiseptic and one disinfectant used in the service. From the analysis performed the first, seventh, fourteenth and twentyfirst day after the opening of the bottles, it was found that the samples retained their activity in vitro antimicrobial regarding standardized strains, as evidenced by the absence of growth of colony-forming units and maintaining the chemical stability. The study demonstrated the efficacy of the samples against analysis microbiological in vitro using standardized microorganisms.
\end{abstract}

Key words: Disinfectants; Antiseptics; Microorganisms.

\section{RESUMEN}

El objetivo del estudio fue determinar la actividad antimicrobiana in vitro de los antisépticos y desinfectante utilizados en el servicio de atención primaria de salud en una ciudad en el norte de Paraná, utilizando microorganismos estandarizado por el Instituto Nacional de Control de Calidad en Salud, Fundación Oswaldo Cruz. Con este fin, se realizó un análisis actividad antimicrobiana y la estabilidad química de tres muestras de un antiséptico y desinfectante utilizado en el servicio. Del análisis realizado en el primer, siete, catorce y veintiuno días, después de la apertura de las botellas, se encontró que las muestras mantuvieron su actividad antimicrobiana in vitro frente a cepas estándar, evidencia la ausencia de crecimiento de unidades formadoras de colonias y el mantenimiento de la estabilidad química. El estudio demostró la eficacia de las muestras en contra de organismos microbiológicos utilizando estandarizados in vitro.

Palabras clave: Desinfectantes; Antiséptico; Microorganismos. 


\section{INTRODUÇÃO}

O desenvolvimento de resistência bacteriana representa um constante desafio em todo o mundo. A presença de microrganismos resistentes a antissépticos e desinfetantes pode ser resultado do uso indiscriminado destes produtos no ambiente hospitalar. Este problema tornou-se evidente em instituições de saúde, sendo agravado ao se identificar um aumento da resistência de microrganismos na comunidade pelo uso inadequado de antissépticos e desinfetantes ${ }^{(1,2)}$. Nesse sentido, o uso contínuo de antissépticos e desinfetantes em ambientes hospitalares pode desencadear resistência bacteriana e em alguns casos contribuir para a resistência a antimicrobianos ${ }^{(1-3)}$.

Mesmo com o aumento do número de microrganismos multiresistentes em ambientes hospitalares e em outros serviços de saúde, os antissépticos e desinfetantes ainda continuam desempenhando um papel importante no controle das infecções hospitalares, atuando de forma a minimizar a disseminação de microrganismos ${ }^{(4)}$.

O conhecimento da atividade antimicrobiana destes produtos frente a microrganismos gram-negativos e gram-positivos é essencial para o estabelecimento de estratégias em relação ao uso racional de antissépticos e desinfetantes nos serviços de saúde ${ }^{(1-3)}$.

Para verificação da qualidade de antissépticos e desinfetantes, vários aspectos como princípio ativo, estabilidade, toxicidade, atividade antimicrobiana entre outros, devem ser considerados e avaliados.

No Brasil a regulamentação dos biocidas está a cargo do Ministério da Saúde, por meio da Divisão de Saneantes Domissanitários (DISAD), que cuida dos saneantes e desinfetantes, e da Divisão de Medicamentos (DIMED), que trata da normatização dos antissépticos ${ }^{(5)}$.

De acordo com a Portaria no 2.616/98, da Agência Nacional de Vigilância Sanitária (ANVISA), que normatiza as diretrizes e normas para a prevenção e o controle das infecções hospitalares, o uso de antissépticos, desinfetantes e esterilizantes nos serviços de saúde deve ser orientado pelas determinações da Portaria $\mathrm{n}^{\circ}$ 15, de 23 de agosto de 1988, da Secretaria de Vigilância Sanitária (SVS) do Ministério da Saúde (MS) e pela publicação Processamento de Artigos e Superfícies em Estabelecimentos de Saúde/ do MS de 1994, ou outras que as complementem ou substituam ${ }^{(6)}$.

A Portaria $n^{\circ}$ 15/88 estabelece que estes produtos somente possam ser registrados e autorizados para uso, mediante a comprovação de sua eficácia aos fins propostos, através de análise prévia realizada com o produto acabado e nas diluições de uso indicadas pelo fabricante. Essas análises devem ser realizadas no Instituto Nacional de Controle de Qualidade em Saúde da Fundação Oswaldo Cruz (INCQS/FIOCRUZ), ou em laboratórios oficiais credenciados especificamente para este fim, obedecidos os métodos e procedimentos preconizados pelo INCQS/FIOCRUZ. Os microrganismos a serem utilizados nos testes devem ser aqueles padronizados pelo INCQS/ FIOCRUZ ou oriundos de Instituições de sua referência( ${ }^{(6)}$.

Os antissépticos e desinfetantes têm em sua composição substâncias químicas como fenol, aldeídos, álcool, biguanidas, metais pesados, peroxigênio, compostos halogenados, e compostos quaternários de amônia. Em geral, estes apresentam maior espectro de ação do que os antibióticos, e agem em múltiplos alvos da parede celular, da membrana citoplasmática e do citoplasma microbiano ${ }^{(1,7)}$.

Os antissépticos são formulações com função de eliminar ou inibir o crescimento de microrganismos quando aplicados sobre a pele ou mucosas. Estes podem ser classificados como agentes bactericidas devido à capacidade de destruir as bactérias nas formas vegetativas, e como agentes bacteriostáticos porque inibem o crescimento do microrganismo sem destruí-lo. Uma característica importante a ser acrescida aos antissépticos é a atividade residual, ou seja, atividade química persistente sobre a pele ${ }^{(8-10)}$.

Já os desinfetantes têm largo espectro de atividade antimicrobiana podendo ser utilizados em várias locais, incluindo a indústria de processamento de alimentos, bebidas, farmacêutica e médico-hospitalar. Seu uso na área hospitalar e em outros serviços de saúde tem grande importância devido às suas propriedades bactericidas, virucidas e fungicidas que causam a inativação de microrganismos na forma vegetativa (não esporulada) em superfícies inanimadas ${ }^{(11)}$.

Nesse sentido, conhecer a atividade antimicrobiana in vitro dos antissépticos e desinfetantes de uso padronizado em serviços de saúde é de extrema importância para se adequar e racionalizar o uso dos mesmos à realidade de cada instituição. Em tempo, a legislação vigente em nosso país estabelece que biocidas devam ser analisados quanto à sua atividade antimicrobiana reforçando a importância deste tipo de avaliação.

Um biocida que apresente uma concentração relativamente inferior a estabelecida pode resultar numa ação insatisfatória frente a microrganismos. Porém o seu uso abusivo pode resultar em sérias intoxicações em pacientes e funcionários, podendo levar até ao óbito ${ }^{(12)}$, além do aumento da sua concentração poder potencializar a ação corrosiva sobre objetos metálicos e mármores ${ }^{(13)}$.

Sendo assim, o presente estudo teve por objetivo determinar in vitro a atividade antimicrobiana e a estabilidade química de antissépticos e de desinfetante utilizados no serviço de atenção primária à saúde de uma cidade do norte do Paraná, utilizando microrganismos padronizados pelo INCQS/ FIOCRUZ.

\section{MÉTODO}

Trata-se de uma pesquisa experimental longitudinal prospectiva, com análise quantitativa. A pesquisa é considerada experimental, quando há controle da situação, podendo-se isolar todas as estruturas de interferências do meio exterior, gerando maior confiabilidade nos resultados. O laboratório é o local ideal para esse tipo de estudo(14). É também considerada um estudo longitudinal quando o objeto é observado em mais de uma ocasião, com objetivo de detectar mudanças ao longo do tempo(15).

Foram avaliados os antissépticos e o desinfetante de uso padronizado em um serviço de atenção primária à saúde de uma cidade do norte do Paraná, durante os meses de agosto 
e setembro de 2008. Como critério de seleção, as amostras deveriam estar dentro do prazo de validade indicado pelo fabricante, e armazenadas em local adequado, seguindo as recomendações contidas no frasco.

Os antissépticos avaliados foram o álcool etílico hidratado $70 \%$, polivinilpirrolidona iodada (PVP-I) tópico 1\% e PVP-I degermante $1 \%$. O desinfetante avaliado foi o hipoclorito de sódio $1 \%$. As amostras dos produtos foram coletadas e analisadas quanto à atividade antimicrobiana mediante autorização formal do responsável pela instituição.

Em todos os testes de avaliação da atividade antimicrobiana dos antissépticos e do desinfetante foram utilizados microrganismos padrões da Fundação Oswaldo Cruz (Rio de Janeiro - RJ), preconizados para a análise de antissépticos e desinfetantes: Staphylococcus aureus - ATCC 6538, Escherichia coli - ATCC 11229, Salmonella choleraesuis - ATCC 10708, Pseudomonas aeruginosa - ATCC15442(4).

Para verificação da esterilidade dos antissépticos e desinfetantes analisados, $1,0 \mathrm{ml}$ de cada produto foi colocado em 4 $\mathrm{ml}$ de Tryptic Soy Broth (TSB). Os tubos foram incubados por $24 \mathrm{~h}$ a $37^{\circ} \mathrm{C}$ e após, semeados em Tryptic Soy ágar (TSA) e ágar MacConkey (MC).

O teste de avaliação da atividade antimicrobiana dos antissépticos e do desinfetante foi realizado de acordo com estudo ${ }^{(16)}$ já realizado com algumas modificações.

As cepas padrões foram inoculadas em $3 \mathrm{ml}$ de TSB (Difco) e incubadas a $37^{\circ} \mathrm{C}$ até atingirem o padrão de turbidez de 1,0 na escala MacFarland ( $10^{8}$ Unidades Formadoras de Colônias/ $\mathrm{ml}$ ). Uma alíquota de 0,2 $\mathrm{ml}$ dessa suspensão foi adicionada a $0,8 \mathrm{ml}$ de soro fetal bovino utilizado como matéria orgânica, sendo essa mistura adicionada a $4,0 \mathrm{ml}$ dos antissépticos e desinfetantes de acordo com a diluição utilizada no hospital. Após a agitação manual durante um minuto os tubos foram deixados a temperatura ambiente durante 10 minutos para os antissépticos e para o desinfetante. Uma alíquota de 0,1 ml dessa mistura foi semeada na superfície de TSA com neutralizante tiossulfato de sódio 0,6\% para os antissépticos e para o desinfetante. As placas foram incubadas durante $24-48 \mathrm{~h}$ a $37^{\circ} \mathrm{C}$ e após foram feitas as contagens das colônias. Como controle negativo foram realizados testes com salina $0,85 \%$ na ausência de material orgânico. O experimento foi realizado em triplicata.

Paralelo à avaliação da atividade antimicrobiana foi realizada a análise de concentração química dos princípios ativos dos antissépticos e do desinfetante, uma vez que a alteração na concentração do princípio ativo pode interferir na atividade antimicrobiana.

A solução de álcool etílico $70 \%$ foi analisada de acordo com a metodologia preconizada pela Farmacopeia Portuguesa. As análises das soluções de PVP-I tópico 1\% e PVP-I degermante $1 \%$ foram realizadas de acordo com metodologia do manual técnico do Departamento de Química da Universidade de Coimbra ${ }^{(17)}$. E a análise da solução hipoclorito de sódio $1 \%$ foi realizada de acordo com a metodologia proposta por Oliveira e Silva ${ }^{(18)}$.

No início do experimento foi coletada uma amostra de 150 $\mathrm{ml}$ de cada produto antisséptico e desinfetante e armazenada em frasco estéril, lacrado, e envolto com papel refletor de luz e calor. Estes frascos foram armazenados ao abrigo da luz e calor, para comparação com as amostras que permaneceram em seus frascos originais passíveis de manipulação periódica. Para efeito de entendimento, essa amostra foi denominada amostra fechada, e a amostra que permaneceu em frasco original, amostra aberta.

Todos os experimentos foram realizados em ambiente asséptico, para evitar contaminação de outros tipos de microrganismos, pois o enfoque do estudo é a utilização microrganismos padrões. As amostras fechadas foram analisadas no vigésimo primeiro dia após aberto o frasco original, sendo submetidas ao teste de esterilidade, ao teste de atividade antimicrobiana e a análise de concentração química. O restante de cada produto foi mantido em seus frascos originais, sendo estes analisados no sétimo, décimo quarto e vigésimo primeiro dias.

No primeiro dia da abertura dos frascos originais, foram realizados os testes de esterilidade dos produtos e análise de concentração química dos mesmos. O teste de esterilidade foi realizado com objetivo de excluir as amostras que apresentassem qualquer tipo de microrganismos, para evitar resultados duvidosos, encontrados no teste de crescimento microbiológico. A análise da concentração química dos produtos foi realizada para identificação de produtos com alteração de concentração, o que poderia interferir nos testes de atividade antimicrobiana.

No sétimo, décimo quarto e vigésimo primeiro dias foram realizados os testes de atividade antimicrobiana e análise de concentração química dos produtos. Para analisar a estabilidade e a atividade antimicrobiana das amostras.

\section{RESULTADOS}

Os resultados dos testes realizados para verificação de esterilidade do álcool etílico 70\%, PVP-I tópico 1\%, PVP-I degermante $1 \%$, e hipoclorito de sódio $1 \%$, no momento da abertura dos frascos originais, demonstraram que os produtos estavam livres de microrganismos, evidenciado pela ausência de crescimento de microrganismos nos meios de cultura TSB, TSA e MC.

O teste também foi aplicado, no vigésimo primeiro dia após a abertura dos frascos originais. às amostras fechadas, não apresentando crescimento de microrganismos comprovado pela ausência de UFCs (unidades formadoras de colônias), nos tubos de TSB, placas de TSA e MC, onde foram semeados os produtos.

Após realização do teste de esterilidade com as amostras fechadas, realizou-se o teste de crescimento microbiológico na presença dos produtos em estudo, não sendo comprovada a existência de crescimento de microrganismos. O álcool $70 \%$, PVP-I tópico 1\%, PVP-I degermante $1 \%$ e hipoclorito de sódio $1 \%$, inibiram o crescimento desses microrganismos padronizados. Não foi detectada a presença de UFCs nas placas de TSA contendo tiossulfato de sódio $0,6 \%$.

Na primeira semana de análise dos produtos, após um período de incubação de $24 \mathrm{~h}$ a uma temperatura de $37^{\circ} \mathrm{C}$ das placas de Petri contendo as soluções de antisséptico e 
desinfetante semeados juntamente com os microrganismos e material orgânico, não houve crescimento microbiológico, o que foi constatado pela ausência de UFCs. O álcool 70\% PVP-I tópico 1\%, PVP-I degermante 1\% e hipoclorito de sódio $1 \%$ inibiram o crescimento dos microrganismos padronizados.

No $14^{\circ}$ dia de analise após incubação de um periodo de $24 \mathrm{~h}$ a uma temperatura de $37^{\circ} \mathrm{C}$, não foi dedectada a presença de qualquer UFC, afirmando a efetividade dos produtos analisados. O álcool 70\%, PVP-I tópico 1\%, PVP-I degermante1\% e hipoclorito de sódio $1 \%$ tem sua efetividade comprovada contra os microrganismos padronizados.

Foi detectada a inibição do crescimento microbiológico após 21 dias da data da abertura do frasco original, fato este comprovado pela ausência de formação de UFCs nas placas onde foram semeados os microrganismos juntamente com o hipoclorito de sódio e os antissépticos.

Paralelo às análises antimicrobianas, realizou-se, semanalmente, as análises das concentrações dos princípios ativos das substâncias estudadas durante três semanas, sendo que uma quantia de amostra foi estocada em um frasco hermeticamente fechado livre da exposição à luz e calor e foi analisada somente na $3^{\mathrm{a}}$ semana. Os resultados da concentração química dos produtos estão apresentados, a seguir, na Tabela 1.

Tabela 1- Concentração química dos produtos. Arapongas/PR, 2008.

\begin{tabular}{c|c|c|c|c|c|c}
\hline Produto & $\begin{array}{c}\text { Concentração } \\
\text { descrita no } \\
\text { rótulo (\%) }\end{array}$ & $\begin{array}{c}\mathbf{1}^{\circ} \text { dia } \\
(\%)\end{array}$ & $\begin{array}{c}7^{\circ} \text { dia } \\
\mathbf{( \% )}\end{array}$ & $\begin{array}{c}\mathbf{1 4}^{\circ} \text { dia } \\
\mathbf{( \% )}\end{array}$ & $\begin{array}{c}\mathbf{2 1}^{\circ} \text { dia } \\
(\%)\end{array}$ & $\begin{array}{c}\mathbf{2 1} \text { dia } \\
\text { amostra } \\
\text { fechada } \\
(\%)\end{array}$ \\
\hline $\begin{array}{c}\text { Álcool } \\
70 \%\end{array}$ & 70 & 70,84 & 69,04 & 68,28 & 67,56 & 68,92 \\
\hline $\begin{array}{c}\text { PVP-I } \\
\text { tópico 1\% }\end{array}$ & 1,0 & 1,07 & 1,03 & 1,02 & 1,02 & 1,02 \\
\hline $\begin{array}{c}\text { PVP-I } \\
\text { degermante } \\
1 \%\end{array}$ & 1,0 & 1,04 & 1,00 & 0,99 & 0,99 & 1,01 \\
\hline $\begin{array}{c}\text { Hipoclorito } \\
\text { de sódio } \\
1 \%\end{array}$ & 1,0 & 1,30 & 1,26 & 1,27 & 1,25 & 1,26 \\
\hline
\end{tabular}

As concentrações dos princípios ativos dos biocidas analisados no primeiro dia estavam concordantes com as concentrações indicadas pelos fabricantes, com exceção do hipoclorito de sódio $1 \%$ que teve um aumento de $30 \%$ da concentração indicada.

A análise da concentração química do álcool corresponde aos valores ideais para uso, tendo um acréscimo de $0,84 \%$ no primeiro dia de análise, porém uma queda no $7^{\circ}, 14^{\circ}, 21^{\circ}$ dia abaixo de $70 \%$, mas que se mantém dentro dos parâmetros aceitáveis, tendo sua efetividade microbiológica evidenciada também, pela sensibilidade dos microrganismos a este produto.

Houve variações quase desprezíveis da concentração dos princípios ativos das soluções durante o período de estudo
(21 dias). O PVP-I tópico 1\% apresentou 1,07\% no primeiro dia, $1,03 \%$ no sétimo dia, $1,02 \%$ no décimo primeiro dia e $1,02 \%$ no vigésimo primeiro dia. Houve, ainda, uma oscilação do PVP-I degermante $1 \%$, que apresentou $1,04 \%$ no primeiro dia, 1,00\% no sétimo dia, 0,99\% no décimo quarto dia e $0,99 \%$ no vigésimo primeiro dia; e, também, uma oscilação do hipoclorito de sódio que apresentou uma concentração inicial de $1,30 \%, 1,26 \%$ no sétimo dia, 1,27\% no décimo quarto dia e 1,26\% no vigésimo primeiro dia.

As variações das concentrações dos princípios ativos das soluções analisadas foram praticamente insignificantes durante o período analisado (21 dias), mostrando sua estabilidade neste intervalo de tempo.

\section{DISCUSSÃO}

Quando ocorre crescimento de microrganismos em antissépticos e desinfetantes, os produtos tornam-se inadequados para uso, já que não estariam correspondendo aos seus objetivos bactericida, fungicida, virucida e tuberculocida, sendo ainda fonte de contaminação se utilizados em serviços de saúde.

Existe grande importância em realizar o teste de esterilidade, já que houve relatos que apontaram a contaminação de amostras de antissépticos e desinfetantes ${ }^{(10)}$. Da mesma forma, em outro estudo ${ }^{(8)}$, encontrou-se algumas soluções antissépticas contaminadas por estafilococos, certos endosporos e bacilos gram-negativos.

Ao discutir a importância do envase nas características dos agentes antissépticos e desinfetantes, nota-se o destaque em relação aos cuidados como proteção da solução da ação da luz solar direta e excesso de calor, pois esses fatores podem interferir na composição química e conseqüentemente na sua ação microbiológica. Os antissépticos e desinfetantes devem ser armazenados em recipientes fechados e devem ser lavados e secos antes do reabastecimento para que não ocorra contaminação das soluções ${ }^{(8,10)}$.

Os produtos contaminados, principalmente os materiais médico-hospitalares, que apresentam microrganismos em decorrência da ineficácia dos procedimentos de desinfecção, ao serem utilizados, podem desencadear infecção no paciente, pela veiculação de patógenos. Não obstante a utilização de materiais médico-hospitalares contaminados, deve-se observar a eficiência dos antissépticos utilizados em procedimentos invasivos.

No ambiente, é comum a presença de pseudomonas ${ }^{(19)}$, que são muito resistentes a atividade química e podem crescer ativamente em alguns desinfetantes e antissépticos tornando-se um grande problemática para os serviços de saúde. Logo, é necessária a conscientização das instituições de saúde, principalmente dos profissionais responsáveis, buscando uma manipulação cuidadosa desses produtos a fim de evitar possíveis contaminações que podem colocar em risco a vida de pacientes e até mesmo dos trabalhadores da instituição.

Deve-se ter cuidados com os compostos de iodo e cloro, como protegê-los da ação da luz ultravioleta e calor, pois estes podem causar sua decomposição química o que leva a redução de seu poder bacteriostático e bactericida(8). 
O hipoclorito aplicado sobre uma superfície apresenta uma eficiência de em média $24 \mathrm{~h}$ devido à volatização do cloro e pela ação inativadora exercida pela luz do ambiente ${ }^{(10)}$. Este desinfetante é altamente instável, podendo haver redução do cloro livre disponível de 40 a 50\% da concentração inicial em um período de 30 dias $^{(8)}$; sendo assim no $21^{\circ}$ dia após aberto o frasco, considerando a afirmação acima, o produto teria em média $31,5 \%$ da sua concentração inicial, apresentando uma concentração de $0,31 \%$, o que pode não ser suficiente para exercer atividade bactericida em sua totalidade.

A análise da concentração química do álcool correspondeu aos valores ideais para uso. O grau de hidratação do álcool etílico é um fator importante para sua atividade antimicrobiana, que decresce acentuadamente em concentrações inferiores a $50 \%$ e superiores a $70 \%{ }^{(5)}$. Soluções com concentrações inferiores a $70 \%$ são mais usadas por reduzirem os efeitos de ressecamento da pele e apresentar menor custo ${ }^{(10)}$.

Esperava-se que as concentrações das soluções dos frascos originais, amostras abertas, tivessem decaimento superior às amostras armazenadas em frascos estéreis, amostras fechadas. Tanto as amostras que permaneceram em frascos originais que foram manuseados semanalmente, quanto as amostras que foram armazenadas em frascos estéreis e protegidos da luz e calor, tiveram decaimentos aproximados da sua composição química. Estes produtos devem possuir concentrações específicas e métodos de aplicação confiáveis que certifiquem uma boa desinfecção do ambiente e superfícies de trabalho ${ }^{(13)}$.

Sabe-se que os testes in vitro conferem apenas a atividade antimicrobiana do produto, mas não a real capacidade de antissepsia e desinfecção de um ambiente que, por sua vez, pode ter diversos fatores interferentes como a presença de matéria orgânica, prejudicando a atividade antimicrobiana do composto ativo ${ }^{(19)}$. Por esta razão, os testes padronizados, ou não, são discutíveis, e não existe um único método de avaliação microbiológica que considere todas as variáveis no contexto geral de antissepsia e desinfecção. O uso de cepas bacterianas padrões e representativas também são questionados, pois, do mesmo modo, não representam as condições reais num processo de desinfecção, já que estão surgindo os microrganismos multirresistentes em ambiente hospitalar ${ }^{(4,20)}$.
Em nosso estudo testamos a viabilidade dos microrganismos, semeando-os em Placas de Petri contendo TSA com tiossulfato de sódio 0,6\% e ágar MC, com auxilio de uma alça de platina e em forma de estrias. Estas placas apresentaram crescimento microbiano, confirmando assim a replicação das bactérias na ausência dos antissépticos e do desinfetante. Esse experimento confirmou o poder microbicida dos produtos, pois na presença dos mesmos houve inibição total do crescimento microbiológico.

\section{CONCLUSÃO}

Os resultados do estudo apontaram a sensibilidade dos microrganismos aos agentes testados, além da estabilidade das amostras e a manutenção do efeito bactericida e bacteriostático. Verificou-se também, através das análises de controle, que as condições de armazenamento das amostras e as técnicas utilizadas para transporte e semeadura não alteraram as culturas. O estudo apresentou atividade antimicrobiana contra Staphylococcus aureus, Escherichia coli, Salmonella choleraesuis e Pseudomonas aeruginosa, que são microrganismos padronizados e extremamente controlados, são puros, não desenvolveram resistência adquirida, eles permanecem com sua estrutura de DNA, sem mutações.

Para efetividade dos antissépticos e desinfetantes faz-se necessário que o profissional de saúde tenha conhecimento sobre as reais condições de ação desses produtos. Deve-se levar em consideração a natureza do material a se desinfetado. Uma área pode necessitar ser esfregada e lavada antes do desinfetante ser aplicado, pois ele pode ter sua ação microbiológica diminuída na presença de matéria orgânica.

Há de se considerar, no entanto, que a análise da efetividade de qualquer agente químico utilizado na assistência à saúde humana se inicia com experimentações in vitro. Sobre essa assertiva, esclarecemos que nosso intuito não foi questionar a fidedignidade das avaliações realizadas pelas agências reguladoras na autorização e controle de produtos utilizados na assistência à saúde. As técnicas utilizadas nesta pesquisa priorizaram, sobretudo, a vivência do método científico e a compreensão dos fenômenos relacionados aos estudos experimentais.

\section{REFERÊNCIAS}

1. McDonnell G, Russell AD. Antiseptics and disinfectants: activity, action, and resistance. Clin. Microbiol Rev. 1999;12(1):147-179.

2. Poole K. Mechanisms of bacterial biocide and antibiotic resistance. Symp. Ser. Soc. Appl Microbiol. 2002;92:55S-64S

3. Reynaldo MB, Flores MB, Viegas CJA, Magariños MC. Eficácia de algunos biocidas contra estafilococos hospitalarios sensibles y resistentes a la meticilina en la provincia de Buenos Aires, Argentina. Rev. Panam. Salud Pública. 2004;16(3):187-192.
4. Romão CMCA, Miyazaki NHT, Motta LLF. Manual de saneantes: métodos para análise microbiológica de saneantes com ação antimicrobiana. Rio de Janeiro: Fundação Oswaldo Cruz/ Instituto Nacional de Controle de Qualidade em Saúde; 1991.

5. Andrade D, Beraldo CC, Watanabe E, Oliveira AB, ItolY. Atividade antimicrobiana in vitro do álcool gel a $70 \%$ frente as bactérias hospitalares e da comunidade. Medicina (Ribeirão Preto) 2007;40(2):250-4.

6. Brasil. Controle de Infecção Hospitalar. Portaria n. 2616, de 12 de maio de 1998. Diário Oficial da União [periódico 
online], Poder Executivo, 13 de maio de 1998 [citado em 09 set 2010]. Disponível em: http://www.anvisa.gov.br/legis/portarias/2616_98.htm

7. Denyer SP, Stewart GSAB. Mechanisms of action of disinfectants. Intern. Biodeter. Biodegr. 1998;41(3):261-268.

8. Rodrigues EAC, Mendonça JS, Amarante JMB, Alves Filho MB, Grinbaum RS, Richtmann R. Infecções Hospitalares: prevenção e controle. São Paulo: Sarvier; 1997.

9. Oliveira AC, Albuquerque CP, Rocha ICM. Infecções Hospitalares: abordagem, prevenção e controle. Rio de Janeiro: Medsi; 1998. p. 139.

10. Couto RC, Pedrosa TMG, Nogueira JM. Infecção hospitalar e outras complicações não-infecciosas da doença epidemiologia, controle e tratamento. Rio de Janeiro: Medsi; 2003. p. 481.

11. Souza JB, Daniel LA. Comparação entre hipoclorito de sódio e ácido peracético na inativação de e. Coli, colifagos e c. Perfringens em água com elevada concentração de matéria orgânica. Eng. Sanit. Ambient. 2005;10(2):111-117.

12. Ramalho RA. Saneantes hospitalares. Serviço Brasileiro de Respostas Técnicas; 2007.

13. Santos LR, Scalco Neto JF, Rizzo NN, Bastiani PV, Oliveira
VM, Boscardin G, et al. Eficácia de desinfetantes e antissépticos empregados no hospital veterinário da UPF (HV-ÚPF) Brasil. Revista FZVA 2007;14(2):156-164.

14. Kerlinger FN. Metodologia da pesquisa em ciências sociais. São Paulo: Editora Pedagógica e Universitária; 1979.

15. Pereira MG. Epidemiologia: teoria e prática. Rio de Janeiro: Guanabara Koogan; 2003.

16. Litsky B, Litsky W. Investigations on decontamination of hospital surfaces by the use of disinfectant-detergents. Am J Public Health Nations Health. 1968;58:534-543.

17. Universidade de Coimbra. Departamento de Química. Análise volumétrica: volumetria de oxidação-redução. [citado em 5 jun 2010] (Manual técnico). Disponível em: https://woc.uc.pt/quimica/getFile.do?tipo $=2 \& i d=697$

18. Oliveira JM, Silva LR. Teor de cloro ativo. Serviço Brasileiro de Respostas Técnicas; 2006.

19. Tortora GJ, Funke BR, Case CL. Microbiologia. $8^{\mathrm{a}}$ ed. Porto Alegre: Artmed; 2005.

20. Souza ACS, Pereira MS, Rodrigues MAV. Descontaminação prévia de materiais médico-cirúrgicos: estudo da eficácia de desinfetantes químicos e água e sabão. Rev. Latino-Am. Enfermagem 1998;6(3):95-105. 